\title{
Changes in crystal phases and morphologies of rare earth hydroxide nitrates with ionic radius
}

\author{
Fumiya SATO ${ }^{\dagger}$, Hitoshi SHIOKAI*, Yusuke YANO*, Masatoshi SUGIURA* and Ryoji TAKAHASHI \\ Department of Chemistry and Biology, Graduate School of Science \& Engineering, Ehime University, \\ 2-5 Bunkyo-cho, Matsuyama 790-8577, Japan \\ *Department of Chemistry, Faculty of Science, Ehime University, 2-5 Bunkyo-cho, Matsuyama 790_8577, Japan
}

\begin{abstract}
Rare earth hydroxide nitrates are prepared from rare earth nitrates by hydrothermal treatment. Three crystal phases, $M(\mathrm{OH})_{3}$ (M1), $M_{2}(\mathrm{OH})_{5.14}\left(\mathrm{NO}_{3}\right)_{0.86} \cdot \mathrm{H}_{2} \mathrm{O}(\mathrm{M} 2)$, and $M_{4} \mathrm{O}(\mathrm{OH})_{9} \mathrm{NO}_{3}(\mathrm{M} 4)$ are identified. The crystal phase systematically changes from $\mathrm{M1}$ to M4 through M2 with decreasing radius of rare earth cation. Morphology of nanocrystal depends on the crystal phase. M1 and M4 phases grow to be nanorod, and M2 to nanoplate.
\end{abstract}

(02017 The Ceramic Society of Japan. All rights reserved.

Key-words : Rare earth hydroxide nitrate, Hydrothermal synthesis, lonic radius, Morphology, Crystal phases

[Received March 31, 2017; Accepted May 25, 2017]

\section{Introduction}

Rare earth hydroxide nitrates (RHNs) $M_{a} \mathrm{O}_{b}(\mathrm{OH})_{c}\left(\mathrm{NO}_{3}\right)_{d} \cdot e \mathrm{H}_{2} \mathrm{O}$ are prepared by hydrothermal treatment of rare earth hydroxides in the presence of nitrate ion. Here, $M$ is rare earth element. Several crystal phases of RHNs, such as $M(\mathrm{OH})_{2}\left(\mathrm{NO}_{3}\right) \cdot \mathrm{H}_{2} \mathrm{O},{ }^{1)-4)}$ $M_{2}(\mathrm{OH})_{5.14}\left(\mathrm{NO}_{3}\right)_{0.86} \cdot \mathrm{H}_{2} \mathrm{O},{ }^{5), 6)} M_{2}(\mathrm{OH})_{5}\left(\mathrm{NO}_{3}\right) \cdot 1.5 \mathrm{H}_{2} \mathrm{O},{ }^{7)-10)}$ and $\mathrm{M}_{4} \mathrm{O}(\mathrm{OH})_{9} \mathrm{NO}_{3},{ }^{10)-12)}$ have been reported. Hereinafter, $M_{2}(\mathrm{OH})_{5.14}\left(\mathrm{NO}_{3}\right)_{0.86} \cdot \mathrm{H}_{2} \mathrm{O}$ is written as $\mathrm{M} 2, M_{4} \mathrm{O}(\mathrm{OH})_{9} \mathrm{NO}_{3}$ as $\mathrm{M} 4$, and hexagonal rare earth hydroxide, $M(\mathrm{OH})_{3}$, as $\mathrm{M} 1$. $M(\mathrm{OH})_{2}\left(\mathrm{NO}_{3}\right) \cdot \mathrm{H}_{2} \mathrm{O}, \mathrm{M} 2$, and $M_{2}(\mathrm{OH})_{5}\left(\mathrm{NO}_{3}\right) \cdot 1.5 \mathrm{H}_{2} \mathrm{O}$ have layer structure. They have anion exchange ability, and interlayer distance varies with the size of exchanged anion.

$\mathrm{Li}$ and Yanagisawa reported that three kinds of yttrium hydroxide nitrates, $\mathrm{Y}(\mathrm{OH})_{3}(\mathrm{M} 1), \mathrm{Y}_{2}(\mathrm{OH})_{5.14}\left(\mathrm{NO}_{3}\right)_{0.86} \cdot \mathrm{H}_{2} \mathrm{O}(\mathrm{M} 2)$ and $\mathrm{Y}_{4} \mathrm{O}(\mathrm{OH})_{9} \mathrm{NO}_{3}(\mathrm{M} 4)$, were prepared by changing $\mathrm{pH}$ and temperature in hydrothermal treatment. ${ }^{13)}$ They also drew a $\mathrm{pH}-$ temperature phase diagram. According to the diagram, M1 forms at $\mathrm{pH}>11$ regardless of hydrothermal temperature. M2 forms at low $\mathrm{pH}$ and low temperature, and $\mathrm{M} 4$ forms at intermediate $\mathrm{pH}$ and high temperature.

It has also been reported that crystal particles of RHNs sometimes show anisotropic growth. From the rod and plate shape RHN crystallites, rare earth oxide nanorod and nanoplate are obtained by calcination of RHNs. In our previous work, $\mathrm{Er}_{2} \mathrm{O}_{3}$ nanorods showed excellent catalytic activity compared to $\mathrm{Er}_{2} \mathrm{O}_{3}$ nanoparticles in the dehydration of 1,4-butanediol to produce 3-buten-1-ol. ${ }^{14)}$ Huang et al. reported that $\mathrm{Au} / \mathrm{Pr}_{6} \mathrm{O}_{11}$ nanorod was more active than $\mathrm{Au} / \mathrm{Pr}_{6} \mathrm{O}_{11}$ isotropic particle in $\mathrm{CO}$ oxidation because $\operatorname{Pr}_{6} \mathrm{O}_{11}$ nanorod easily released surface and lattice oxygen. ${ }^{15)}$ There have also been reported the catalytic advantage in $\mathrm{CeO}_{2}$ nanorod and nanoplate. ${ }^{16), 17)} \mathrm{Zhong}$ et al. reported that $\mathrm{Eu}^{3+}$-doped $\mathrm{Y}_{2} \mathrm{O}_{3}$ nanorod bundle showed strong red emission at around $613 \mathrm{~nm} .{ }^{18)}$ Because morphology has a high impact on catalytic activity, establishment of the morphology-control method is required. However, factors of determining morphology are still not clear.

$\dagger$ Corresponding author: F. Sato; E-mail: fumiya@ehime-u.ac.jp

* Preface for this article: Dol http://doi.org/10.2109/jcersj2.125.P10-1
In this work, RHNs $(M=\mathrm{Sc}, \mathrm{Y}, \mathrm{La}-\mathrm{Nd}, \mathrm{Sm}-\mathrm{Lu})$ were prepared under three $\mathrm{pH}$ conditions and we investigate crystal phase, chemical composition, and morphology due to clarify factor of determining RHN morphology.

\section{Experimental}

In the preparation of RHNs, rare earth nitrates were used as a rare earth source. Rare earth nitrates were purchased from Sigma-Aldrich $(M=\mathrm{Sc}, \mathrm{Y}, \mathrm{Ce}-\mathrm{Nd}, \mathrm{Sm}-\mathrm{Tb}, \mathrm{Er}, \mathrm{Tm}, \mathrm{Lu})$, Kanto Chemical Co., Inc. $(M=\mathrm{Dy})$, and Wako Pure Chemical Industries, Ltd. $(M=\mathrm{La}, \mathrm{Ho}, \mathrm{Yb}) .25 \mathrm{wt} \%$ aqueous ammonia (Wako Pure Chemical Industries, Ltd.) was used as a pH adjuster. RHNs were prepared with a hydrothermal synthesis method. Rare earth nitrate $\left(2.27-4.40 \mathrm{~g}\right.$, as $1.0 \mathrm{~g}$ of $\left.\mathrm{M}_{2} \mathrm{O}_{3}\right)$ was dissolved in $25 \mathrm{~mL}$ of distilled water. Then, the $\mathrm{pH}$ of the solution was adjusted to 7.0, 8.0 and 9.0 with $25 \mathrm{wt} \%$ aqueous ammonia with stirring for precipitation. No additives such as amine, fatty acid, or alcohol were added. The solution and precipitate were transferred into a $50 \mathrm{~cm}^{3}$ Teflon-lined autoclave. Hydrothermal treatment was carried out at $150^{\circ} \mathrm{C}$ for $24 \mathrm{~h}$. We confirmed that the solution $\mathrm{pH}$ did not change largely during the treatment. The resulting precipitate was washed and dried at $110^{\circ} \mathrm{C}$ for $12 \mathrm{~h}$. The prepared RHN is named as "M-pH (adjusted $\mathrm{pH}$ value)".

X-ray diffraction (XRD) patterns were recorded on an XRD7000 (Shimadzu) using $\mathrm{CuK} \alpha$ radiation to determine crystal phase of RHNs. The fractions of $\mathrm{N}$ and $\mathrm{H}$ in the samples were analyzed in a CHN analyzer (J-SCIENCE LAB ltd., MICRO CORDER JM10T), where gasification temperature was $1000^{\circ} \mathrm{C}$. The thermogravimetry-differential thermal analysis (TG-DTA) was performed by EXSTAR 6000 (Seiko Instruments Inc.) from 30 to $1000^{\circ} \mathrm{C}$ under the following conditions: nitrogen flow rate, $100 \mathrm{~cm}^{3} \mathrm{~min}^{-1}$; heating rate, $10^{\circ} \mathrm{C} \mathrm{min}^{-1}$; sample weight, ca. $3 \mathrm{mg}$. Scanning electron microscope (SEM) images were taken on a JEOL JSM-7001FA microscope operated at 5 and $15 \mathrm{kV}$. Fourier transform infrared (IR) spectra were measured on a Nicolet iS5 (Thermo Fisher scientific) equipped with Attenuated Total Reflection (ATR) unit. The spectra were taken in reflectance at room temperature with 32 scans accumulated at a spectral resolution of $4 \mathrm{~cm}^{-1}$. 


\section{Results and discussion}

\subsection{Crystal phase}

Figure 1(a) shows XRD patterns of RHNs which were prepared at $\mathrm{pH} 7$. Sm-pH 7 is identified as $\mathrm{Sm}(\mathrm{OH})_{3}$ (JCPDS 6-0117), M1, whose space group is hexagonal $P 6_{3} / m$. La-pH 7, Pr-pH 7 and Nd-pH 7 were not obtained because no precipitation occurred. When rare earth nitrate is used as a rare earth source, light rare-earth (i.e. $\mathrm{La}, \mathrm{Pr}$ and $\mathrm{Nd}$ ) hydroxides precipitate at a $\mathrm{pH}$ value of higher than $7 .{ }^{19)}$ Scandium nitrate solution became jelly-like substance during addition of aqueous ammonia. For this reason, $\mathrm{pH}$ control of the scandium solution is not able. At $M=$ $\mathrm{Ce}$, cerium dioxide precipitated during the $\mathrm{pH}$ adjustment. In the pattern of Gd-pH 7, there are three peaks at $2 \theta$ value of 10.55 , 21.21 , and 28.07 degree corresponding to interplanar distance $(d)$ of $0.838,0.419$, and $0.318 \mathrm{~nm}$, respectively. Because 0.419 is just a half of 0.838 , crystal structure of Gd-pH 7 is probably layer. The pattern of Dy-pH 7 is much like Gd-pH 7. Diffraction peaks of Er-pH 7 appear at $d$ value of $0.908,0.455$, and $0.309 \mathrm{~nm}$. The ratio of $d$ value of the first one to the second one is 1.0 to 0.5 , which suggests that Er-pH 7 is layer structure whose interlayer spacing is longer than Gd-pH 7 irrespective of the smaller cationic radius of Er than Gd. XRD patterns of Ho-pH 7 and Y-pH 7 also show layer-like structures whereas whose peak at around 10 degree is split. There are a lot of peaks in the pattern of $\mathrm{Yb}-\mathrm{pH}$ 7. Figure 1(b) shows XRD patterns of RHNs prepared at $\mathrm{pH}$ 9. Sm-pH 9 and Gd-pH 9 are identified to hexagonal rare earth hydroxide. The pattern of Y-pH 9 is well accorded with
$\mathrm{Y}_{4} \mathrm{O}(\mathrm{OH})_{9} \mathrm{NO}_{3}$, M4, whose space group is monoclinic $P 2_{1}{ }^{11}{ }^{1}$ In previous work, $\mathrm{Y}_{4} \mathrm{O}(\mathrm{OH})_{9} \mathrm{NO}_{3}$ was obtained at an adjusted $\mathrm{pH}$ value of 9 when a $\mathrm{pH}$ adjuster was $\mathrm{NH}_{4} \mathrm{NO}_{3}{ }^{13)}$ Our result replicated the previous work. Diffraction patterns of Ho-pH 9, Er-pH 9, and Yb-pH 9 are similar to that of Y-pH 9. The pattern of Dy-pH 9 is a cross between Gd-pH 9 and Ho-pH 9 patterns. In summary, there are three crystal phases of RHNs such as hexagonal hydroxide, layer, and monoclinic one. The diffraction patterns of these phases are similar to those of M1, M2 and M4 observed for yttrium. ${ }^{13)}$ Hereinafter, we also use these abbreviations to the RHNs.

Table 1 lists crystal phases of RHNs and ionic radius of rare earth cation $\left(r_{\mathrm{i}}\right)$ whose valence is three and coordination number is six. ${ }^{20)} \mathrm{M} 1$ phase is obtained when $r_{\mathrm{i}}$ is large such as $\mathrm{La}, \mathrm{Pr}, \mathrm{Nd}$ and $\mathrm{Sm}$ whereas M4 phase forms at small $r_{\mathrm{i}}$. M2 phase forms at middle $r_{\mathrm{i}}$ and low $\mathrm{pH}$.

Thus, it is clear that the crystal phase of RHNs systematically changes with not only temperature and $\mathrm{pH}$ as reported by $\mathrm{Li}$ and Yanagisawa ${ }^{13)}$ but also with ionic radius of rare earth cation.

\subsection{Determination of chemical composition}

We have identified the crystal phases of RHNs obtained in this work according to those of yttrium reported by $\mathrm{Li}$ and Yanagisawa based on the XRD patterns. In order to confirm the identification, ATR-IR, TG-DTA and CHN analysis were carried out.

\subsubsection{ATR-IR observation}

ATR-IR measurements were performed in order to clarify the

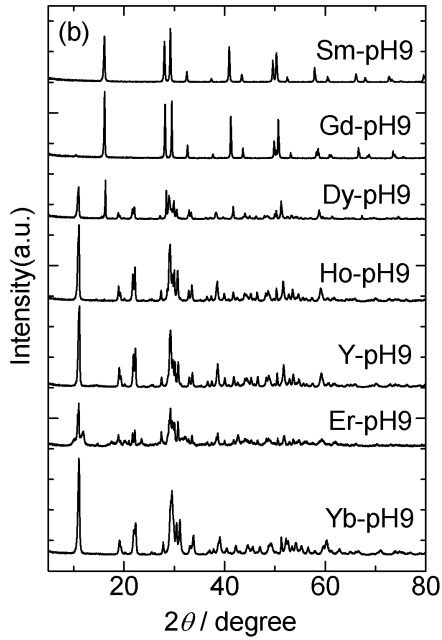

Fig. 1. XRD patterns of rare earth hydroxide nitrates prepared at $\mathrm{pH} 7$ (a) and $\mathrm{pH} 9$ (b).

Table 1. Crystal phases and morphologies of rare earth hydroxide nitrates

\begin{tabular}{|c|c|c|c|c|c|c|c|c|c|c|c|c|c|c|}
\hline$M$ & $\mathrm{Lu}$ & $\mathrm{Yb}$ & Tm & Er & Ho & $\mathrm{Y}$ & Dy & $\mathrm{Tb}$ & Gd & $\mathrm{Eu}$ & $\mathrm{Sm}$ & $\mathrm{Nd}$ & $\operatorname{Pr}$ & $\mathrm{La}$ \\
\hline$r_{\mathrm{i}}(\mathrm{pm})^{\mathrm{a})}$ & 86 & 87 & 88 & 89 & 90 & 90 & 91 & 92 & 94 & 95 & 96 & 98 & 99 & 103 \\
\hline \multicolumn{15}{|c|}{ Crystal phase ${ }^{\mathrm{b})}$} \\
\hline pH 7 & M4 & M4 & M4 & M2 & M2 & M2 & M2 & M2 & M2 & $\mathrm{M} 1+\mathrm{M} 2$ & M1 & - & - & - \\
\hline pH 8 & M4 & M4 & M4 & M4 & M4 & M2 & M2 & M2 & M1 & M1 & M1 & M1 & M1 & M1 \\
\hline pH 9 & M4 & M4 & M4 & M4 & M4 & M4 & $\mathrm{M} 1+\mathrm{M} 4$ & M1 & M1 & M1 & M1 & M1 & M1 & M1 \\
\hline \multicolumn{15}{|c|}{ Morphology $y^{\mathrm{c}}$} \\
\hline pH 7 & $\mathrm{R}$ & $\mathrm{R}$ & B & $\mathrm{P}$ & $\mathrm{P}$ & $\mathrm{P}$ & $\mathrm{P}$ & B & B & B & $\mathrm{R}$ & & & \\
\hline $\mathrm{pH} 8$ & $\mathrm{R}$ & $\mathrm{R}$ & $\mathrm{R}$ & $\mathrm{R}$ & $\mathrm{R}$ & $P$ & $P$ & $\mathrm{P}$ & $\mathrm{R}$ & $\mathrm{R}$ & $\mathrm{R}$ & $\mathrm{R}$ & $\mathrm{R}$ & $\mathrm{R}$ \\
\hline pH 9 & $\mathrm{R}$ & $\mathrm{R}$ & $\mathrm{R}$ & $\mathrm{R}$ & $\mathrm{R}$ & $\mathrm{R}$ & $\mathrm{R}$ & $\mathrm{R}$ & $\mathrm{R}$ & $\mathrm{R}$ & $\mathrm{R}$ & $\mathrm{R}$ & $\mathrm{R}$ & $\mathrm{R}$ \\
\hline
\end{tabular}

a) $r_{\mathrm{i}}$ : ionic radius of rare earth cation (valence $=3$ and coordination number $=6$ ) ${ }^{20}$ )

b) $\mathrm{M} 1, M(\mathrm{OH})_{3} ; \mathrm{M} 2, M_{2}(\mathrm{OH})_{5.14}\left(\mathrm{NO}_{3}\right)_{0.86} \cdot \mathrm{H}_{2} \mathrm{O} ; \mathrm{M} 4, M_{4} \mathrm{O}(\mathrm{OH})_{9} \mathrm{NO}_{3}$.

c) R, nanorod; $\mathrm{B}$, nanobelt; $\mathrm{P}$, nanoplate. 
components existing in the samples. Figure 2 shows ATR-IR spectra of Sm-pH 7, Ho-pH 7, and Yb-pH 8, with M1, M2, and M4 phases, respectively. In order to assign the absorption band of nitrate ion, spectrum of sodium nitrate anhydride is also plotted on Fig. 2. In the spectrum of Sm-pH 7, only one peak is observed at around $3600 \mathrm{~cm}^{-1}$, and it is ascribed to $\mathrm{O}-\mathrm{H}$ stretching vibration. There are three absorption bands in the ATR-IR spectrum of Ho-pH 7. A broad band from 3000 to $3700 \mathrm{~cm}^{-1}$ can be attributed to crystalline water, which is often accompanied by a weak absorption band at $1615-1640 \mathrm{~cm}^{-1}$.21) Because the remaining peak at ca. $1350 \mathrm{~cm}^{-1}$ appears in the same wavenumber as the only absorption band of $\mathrm{NaNO}_{3}$ anhydrate, this peak can be ascribed to that of nitrate ion. In the spectrum of $\mathrm{Yb}-\mathrm{pH} 8$, multiplet and doublet absorption bands are observed at 32003700 and $1200-1500 \mathrm{~cm}^{-1}$, corresponding to absorption of $\mathrm{OH}$ group and nitrate ion, respectively. Thus, it is assured that M1 phase contains only $\mathrm{OH}$, and that $\mathrm{M} 2$ and M4 phases contain both $\mathrm{OH}$ and $\mathrm{NO}_{3}{ }^{-}$. It is also speculated from the broadening of $\mathrm{OH}$ band in $\mathrm{M} 2$ phase that the local structure of $\mathrm{OH}$ has wide variety due to hydrogen bonding. On the other hand, the sharpness and/or multiplet of $\mathrm{OH}$ bands in M1 and M4 phases suggest that the $\mathrm{OH}$ bonds in these samples are fixed at specific crystallographic positions. Additionally, the doublet and sharpness of $\mathrm{NO}_{3}{ }^{-}$bands in $\mathrm{M} 4$ phase suggest that $\mathrm{NO}_{3}{ }^{-}$is also fixed. These results well agree with the crystallographic structure of each phase. ${ }^{11)}$

\subsubsection{M1 phase}

From the ATR-IR result, it is clear that nitrogen content of M1 phase is zero. According to $\mathrm{CHN}$ analysis results, nitrogen

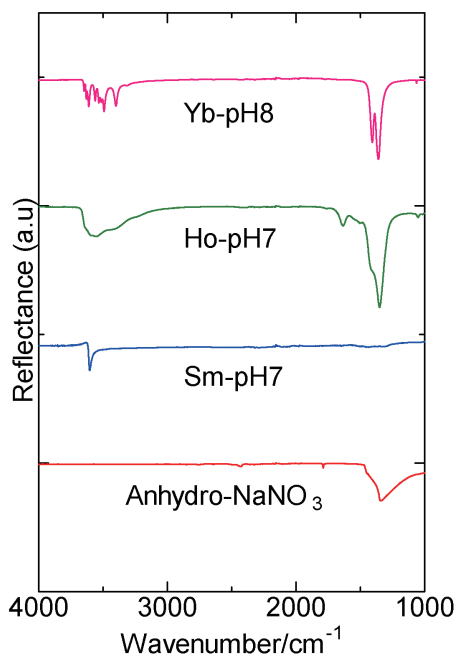

Fig. 2. ATR-IR spectra of $\mathrm{NaNO}_{3}$ anhydrate, $\mathrm{Sm}-\mathrm{pH} 7$, Ho-pH 7, and $\mathrm{Yb}-\mathrm{pH} 8$. fraction of M1 phase RHNs is less than $0.50 \mathrm{wt} \%$ : Pr-pH 9, 0.12; Sm-pH 9, 0.33; Gd-pH 9, 0.43; Tb-pH 9, 0.13; and Sm-pH 7, $0.21 \mathrm{wt} \%$. These values can be regarded as 0 because of the experimental error. Figure 3(a) shows TG-DTA curves of Sm$\mathrm{pH}$ 7. Experimental weight loss from 30 to $1000^{\circ} \mathrm{C}$ is $13.2 \mathrm{wt} \%$, which is consistent with the theoretical value $\{13.4 \mathrm{wt} \%$, $\left.2\left[\mathrm{Sm}(\mathrm{OH})_{3}\right] \rightarrow \mathrm{Sm}_{2} \mathrm{O}_{3}\right\}$. Thus, there is little doubt that M1 phase is rare earth hydroxide $M(\mathrm{OH})_{3}$. Sm-pH 7 is decomposed by two endothermic steps, and those weight losses are $8.8 \mathrm{wt} \%$ at around $340^{\circ} \mathrm{C}$ and $4.4 \mathrm{wt} \%$ at ca. $450^{\circ} \mathrm{C}$. Possible thermal decomposition processes are as follows:

$$
\begin{array}{ll}
\mathrm{Sm}(\mathrm{OH})_{3} \rightarrow \mathrm{SmOOH}+\mathrm{H}_{2} \mathrm{O} \uparrow & \left(290-370^{\circ} \mathrm{C}\right) \\
2 \mathrm{SmOOH} \rightarrow \mathrm{Sm}_{2} \mathrm{O}_{3}+\mathrm{H}_{2} \mathrm{O} \uparrow & \left(400-480^{\circ} \mathrm{C}\right)
\end{array}
$$

\subsubsection{M2 phase}

Chemical formula of M2 phase has been reported to be $\mathrm{Y}_{2}(\mathrm{OH})_{5.14}\left(\mathrm{NO}_{3}\right)_{0.86} \cdot \mathrm{H}_{2} \mathrm{O} .{ }^{13)}$ The ATR-IR result does not contradict from this identification. Figure 3(b) shows TG-DTA profiles of Er-pH 7. Measured weight loss is $22.4 \mathrm{wt} \%$, and it is in good harmony with the estimated loss $\left[22.5 \mathrm{wt} \%, \mathrm{Er}_{2}(\mathrm{OH})_{5.14^{-}}\right.$ $\left(\mathrm{NO}_{3}\right)_{0.86} \cdot \mathrm{H}_{2} \mathrm{O} \rightarrow \mathrm{Er}_{2} \mathrm{O}_{3}$ ]. Thermal decomposition of Er-pH 7 proceeds in three endothermic steps. We estimate chemical equation of each step by reference to $\mathrm{Y}_{2}(\mathrm{OH})_{5.14}\left(\mathrm{NO}_{3}\right)_{0.86} \cdot \mathrm{H}_{2} \mathrm{O}$. $\left.{ }^{5}\right)$ The first and moderate weight decrease up to $270^{\circ} \mathrm{C}$ is $3.5 \%$ consistent with a single molecule of hydrated water (theoretical value, $3.7 \%$ ). The second loss around $300^{\circ} \mathrm{C}$ can be ascribed to two water molecules. The final weight loss is gasification of the remaining nitrogen and hydrogen components as nitrogen oxide and water, respectively. That is, thermal decomposition steps are probably as follows:

$$
\begin{array}{r}
\mathrm{Er}_{2}(\mathrm{OH})_{5.14}\left(\mathrm{NO}_{3}\right)_{0.86} \cdot \mathrm{H}_{2} \mathrm{O} \rightarrow \mathrm{Er}_{2}(\mathrm{OH})_{5.14}\left(\mathrm{NO}_{3}\right)_{0.86}+\mathrm{H}_{2} \mathrm{O} \uparrow \\
\left(<270^{\circ} \mathrm{C}\right) \\
\mathrm{Er}_{2}(\mathrm{OH})_{5.14}\left(\mathrm{NO}_{3}\right)_{0.86} \rightarrow \mathrm{Er}_{2} \mathrm{O}_{2}(\mathrm{OH})_{1.14}\left(\mathrm{NO}_{3}\right)_{0.86}+2 \mathrm{H}_{2} \mathrm{O} \uparrow \\
\left(270-350^{\circ} \mathrm{C}\right) \\
\mathrm{Er}_{2} \mathrm{O}_{2}(\mathrm{OH})_{1.14}\left(\mathrm{NO}_{3}\right)_{0.86} \rightarrow \mathrm{Er}_{2} \mathrm{O}_{3}+0.57 \mathrm{H}_{2} \mathrm{O} \uparrow+\mathrm{NO}_{x} \uparrow
\end{array}
$$$$
\left(475-550^{\circ} \mathrm{C}\right)
$$

Nitrogen content of Er-pH 7 (2.41 wt\%) and Gd-pH 7 $(2.75 \mathrm{wt} \%)$ are consistent with calculated values, $2.44 \mathrm{wt} \%$ of $\mathrm{Er}_{2}(\mathrm{OH})_{5.14}\left(\mathrm{NO}_{3}\right)_{0.86} \cdot \mathrm{H}_{2} \mathrm{O}$ and $2.55 \mathrm{wt} \%$ of $\mathrm{Gd}_{2}(\mathrm{OH})_{5.14^{-}}$ $\left(\mathrm{NO}_{3}\right)_{0.86} \cdot \mathrm{H}_{2} \mathrm{O}$, respectively.

\subsubsection{M4 phase}

As described in Section 3.1, XRD pattern of M4-phase is similar to that of $\mathrm{Y}_{4} \mathrm{O}(\mathrm{OH})_{9} \mathrm{NO}_{3}$. Thus, chemical composition of M4 phase is supposed to be $M_{4} \mathrm{O}(\mathrm{OH})_{9} \mathrm{NO}_{3}$. Figure 3(c) shows TG-DTA curves of Y-pH 9. Thermal decomposition of Y-pH 9 proceeds in two endothermic steps, 310-410 and 460$550^{\circ} \mathrm{C}$. This result is consistent with TGA-DSC measurement of $\mathrm{Y}_{4} \mathrm{O}(\mathrm{OH})_{9} \mathrm{NO}_{3}$ in the previous study. ${ }^{10)}$ Total experimental weight loss is $23.9 \%$, which is slightly higher than theoretical weight
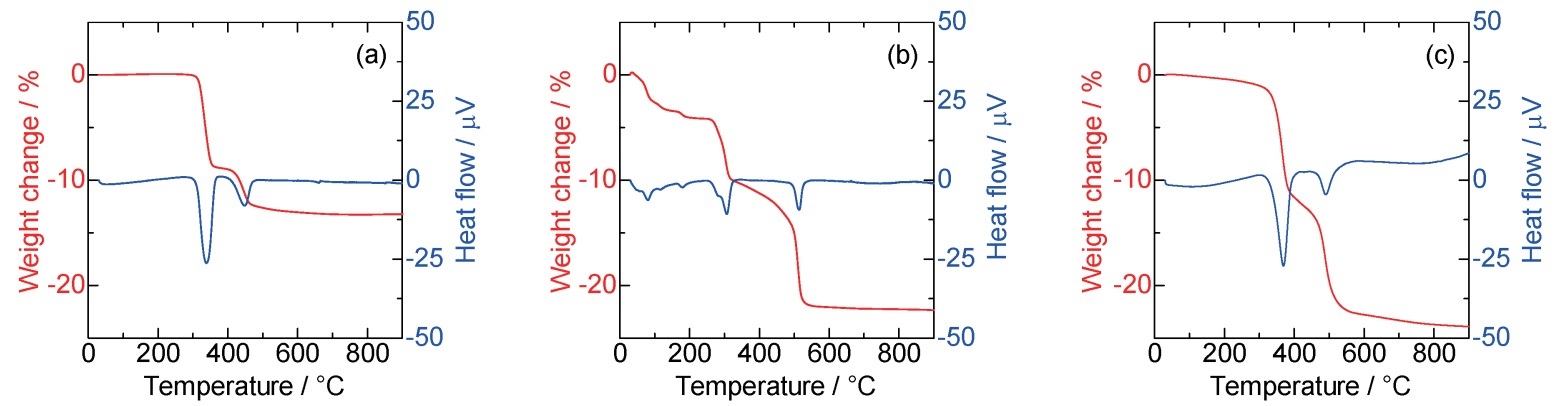

Fig. 3. TG-DTA curves of Sm-pH 7 (a), Er-pH 7 (b), and Y-pH 9 (c), which are M1, M2, and M4 phases, respectively. 


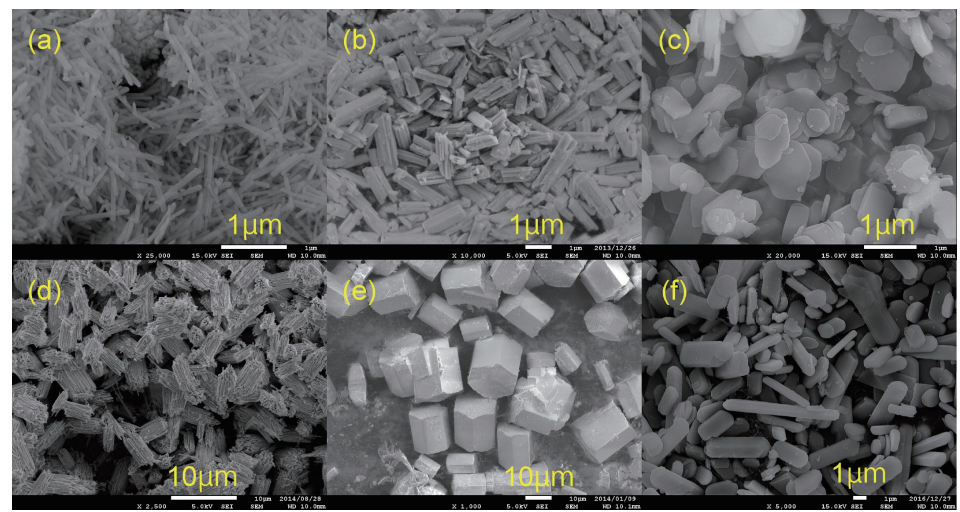

Fig. 4. SEM images of Nd-pH 9 (a), Er-pH 9 (b), Y-pH 7 (c), Yb-pH 8 (d), Sm-pH 7 (e), and Eu-pH 7 (f)

decrease $(23.0 \%)$. However, we were unable to estimate chemical equation of each step because we couldn't find any reasonable intermediate. In fact, Zhang et al. also failed to determine thermal decomposition mechanism of $\mathrm{Y}_{4} \mathrm{O}(\mathrm{OH})_{9}\left(\mathrm{NO}_{3}\right) .{ }^{10)}$ According to $\mathrm{CHN}$ elemental analysis, measured nitrogen content $(1.56 \mathrm{wt} \%$ in Ho-pH 9) accords closely with theoretical one (1.57 wt \%). These results suggest that chemical formula of M4 phase is $M_{4} \mathrm{O}(\mathrm{OH})_{9} \mathrm{NO}_{3}$.

\subsection{Morphology}

Figures 4(a)-4(f) show SEM images of some samples. We can categorize the morphology into 3 types, nanorod, nanobelt, and nanoplate as summarized in Table 1. Figure 4(a) shows SEM image of Nd-pH 9. This sample is nanorod with high-aspect ratio, which is ca. $1 \mu \mathrm{m}$ long and approximate $50 \mathrm{~nm}$ diameter. Similar nanorod formed at $M=\mathrm{La}$ and $\mathrm{Pr}$ with large cation. On the other hand, Er-pH 9 with small cation is rugged nanorod with low-aspect ratio [Fig. 4(b)]. This nanorod is similar to trilobal $\mathrm{Y}_{4} \mathrm{O}(\mathrm{OH})_{9} \mathrm{NO}_{3}$ reported by Hong et al. ${ }^{12)}$ Similar nanorod is observed in Ho-pH 8 and Ho-pH 9 with M4 phase. Figure 4(c) shows SEM image of Y-pH 7, and the shape of sample is nanoplate. Nanoplate formed at low $\mathrm{pH}$ and middle $r_{\mathrm{i}}$. $\mathrm{Yb}-\mathrm{pH} 8$ seems to be a bundle of many slim nanorods [Fig. 4(d)]. The bundle structure is also observed in Lu-pH 8. Sm-pH 7 is honeycomb-like hexagonal column, which is $15 \mu \mathrm{m}$ long and ca. $10 \mu \mathrm{m}$ wide on each side [Fig. 3(e)]. Eu-pH 7 is nanobelt, which is thinner than nanorod [Fig. 3(f)]. As listed in Table 1, morphology of RHNs is rod when the ion radius is small and large whereas plate and belt-shape particle are observed when $r_{\mathrm{i}}$ is middle. Thus, it is clear that the crystal phase of RHNs systematically changes with ionic radius of rare earth cation.

Here, the relationship between crystal phase of prepared RHN and morphology is as follows:

$$
\begin{array}{lll}
\text { M1 phase } & M(\mathrm{OH})_{3} & \text { Rod } \\
\text { M2 phase } & M_{2}(\mathrm{OH})_{5.14}\left(\mathrm{NO}_{3}\right)_{0.86} \cdot \mathrm{H}_{2} \mathrm{O} & \text { Plate and belt } \\
\text { M4 phase } & M_{4} \mathrm{O}(\mathrm{OH})_{9} \mathrm{NO}_{3} & \text { Rod }
\end{array}
$$

The relationship between crystal phase and morphology is almost one-to-one correspondence. These results indicate RHN morphology depends on crystal phase of RHN.

\subsection{Possible crystal growing scheme}

We can explain the origin of morphology based on crystal structure of RHN. Figure 5(a) is crystal structure of hexagonal M1 phase. Because M1 phase is six-fold symmetry, crystal growth rate along $a$ axis can be the same as that along $b$ axis. Morphology of Nd-pH 9 with M1 phase is nanorod as shown in
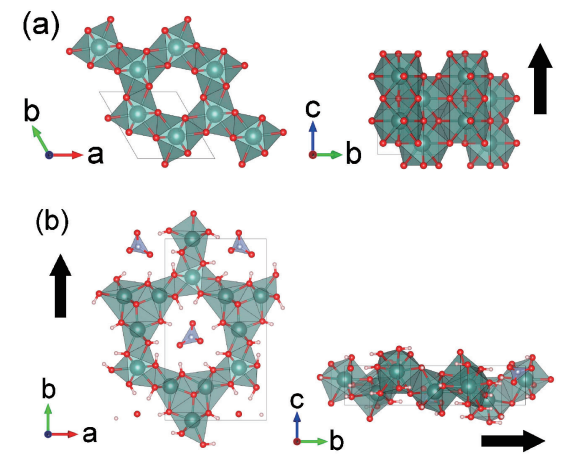

Fig. 5. Crystal structures of hexagonal $M(\mathrm{OH})_{3}$ (a) and monoclinic $M_{4} \mathrm{O}(\mathrm{OH})_{9} \mathrm{NO}_{3}$ (b). Green large ball, rare earth $(M)$; gray ball, nitrogen; red ball, oxygen; bright pink ball, hydrogen. Bold black arrow represents possible crystal growth direction. These figures were drawn by VESTA. ${ }^{22}$ )

Fig. 4(a). This result indicates crystal growth rate along $c$-axis is probably faster than other axes. Figure 5(b) is crystal structure of M4 phase. There is a channel in a direction to $c$-axis and nitrate ions locate in the channel. Comparing length of cell edges, $a, b$ and $c, b$ is longer than $a$ and $c$. Because of anisotropy of monoclinic structure, M4 phase seems to grow intrinsically as rod-shape crystal. In other words, crystal with M4 phase may grow along $b$-axis. However, morphology of M4 phase samples is not simple nanorod but trilobal-like nanorod and bundle shapes. Zhang et al. suggested that the trilobal nanorod formed by self-assemblage of three rod-like nanocrystals because crystalline size might be too small to maintain single particle with stability. ${ }^{10)}$ Thus, Er-pH 9 [Fig. 4(b)] is an aggregate of several nanorods. Yb-pH 8 [Fig. 4(d)] also seems to be the aggregate whereas the number of nanorods constituting $\mathrm{Yb}-\mathrm{pH} 8$ is much more than Er-pH 9. Since surface energy probably affects the stability of nanorods, narrow nanorods tend to aggregate much more than wideness. However, average width of these nanorods is unable to measure due to lose shape. Morphology of Sm-pH 7 with M1 phase is honeycomb-like hexagonal column [Fig. 4(e)]. The column seems to form by dissolution and recrystallization process of bundle. In fact, surface of the column is smooth and cross-sectional shape is hexagonal. Samarium hydroxide dissolves in aqueous solution easier than other rare earth hydroxides at the same $\mathrm{pH}^{19}{ }^{19}$ Additionally, Hong et al. reported dissolution and recrystallization proceeded at $\mathrm{pH} 7$ whereas did not at $\mathrm{pH}$ 9. ${ }^{12)} \mathrm{M} 2$ phase has layer structure although space group remains undetermined. Layer crystal is known to form nanoplate as shown in Fig. 4(c) due to a slow growing rate for direction of 
stacking. Morphology of Eu-pH 7 with M2 phase is nanobelt [Fig. 4(f)]. However, layer phase is unlikely to grow uniaxially. We presume that rod-shape particles exist before hydrothermal process and these particles become thin into belt-like shape with crystal phase transition into M2 phase during hydrothermal process.

\section{Conclusion}

RHNs are prepared from all rare earth nitrate except $M=\mathrm{Pm}$ under the conditions of $150^{\circ} \mathrm{C}$ and $\mathrm{pH}$ between 7 and 9. At $M=\mathrm{Sc}, \mathrm{pH}$ control of the scandium solution is not able because of formation of jelly-like substance during addition of aqueous ammonia. At $M=\mathrm{Ce}$, cerium dioxide precipitated during the $\mathrm{pH}$ adjustment. There are three crystal phases of RHNs such as hexagonal M1 phase, layer M2 phase, and monoclinic M4 phase. Crystal phase changes from M4 to M1 through M2 phase with increasing ionic radius of rare earth cation. Chemical composition of RHNs is determined by ATR-IR, TG-DTA and a CHN analysis: $\mathrm{M} 1, M(\mathrm{OH})_{3} ; \mathrm{M} 2, M_{2}(\mathrm{OH})_{5.14}\left(\mathrm{NO}_{3}\right)_{0.86} \cdot \mathrm{H}_{2} \mathrm{O} ; \mathrm{M} 4$, $M_{4} \mathrm{O}(\mathrm{OH})_{9} \mathrm{NO}_{3}$. Morphology of RHNs is rod when the ion radius is small and large whereas plate and belt-shape particle are observed when the ion size is middle. The relationship between crystal phase and morphology is almost one-to-one correspondence: M1 phase, rod; M2 phase, plate and belt; M4 phase, rod. These results indicate RHN morphology depends on crystal phase of RHN.

Acknowledgments This work is financially aided by Nippon Sheet Glass Foundation for Materials Science and Engineering. This work was partially supported by JSPS KAKENHI Grant Number JP 26420708. The CHN analysis, ATR-IR, TG-DTA measurement, and SEM observation experiment were carried out at the Advanced Research Support Center, Ehime University.

\section{References}

1) M. Lundberg and A. J. Skarnulis, Acta Crystallogr., B32, 2944-2947 (1976).
2) S. P. Newman and W. Jones, J. Solid State Chem., 148, 26-40 (1999).

3) D. Louër, F. Deneuve, C. Herviou and C. Gourlaouen, Powder Diffr., 1, 263-264 (1986).

4) J. M. Haschke, Inorg. Chem., 13, 1812-1818 (1974).

5) C. E. Holcombe, Jr., J. Am. Ceram. Soc., 61, 481-486 (1978).

6) Y. Q. Jia, J. G. Li, Y. M. Wang, L. X. Ding, X. M. Qin and X. D. Sun, Acta Metall. Sin., 12, 1188-1193 (1999).

7) L. J. McIntyre, L. K. Jackson and A. M. Fogg, Chem. Mater., 20, 335-340 (2008).

8) K.-H. Lee and S.-H. Byeon, Eur. J. Inorg. Chem., 2009, 929936 (2009).

9) S. A. Hindocha, L. J. McIntyre and A. M. Fogg, J. Solid State Chem., 182, 1070-1074 (2009).

10) J. Zhang, Z. Liu, J. Lin and J. Fang, Cryst. Growth Des., 5, 1527-1530 (2005).

11) A. N. Christensen, M. Nielsen, K. P. J. O'Reilly and T. Wroblewski, Acta Chem. Scand., 46, 224-230 (1992).

12) Z. Hong, H. Guo, L. Peng and M. Wang, Key Eng. Mat., 336338, 2176-2178 (2007).

13) N. Li and K. Yanagisawa, J. Solid State Chem., 181, 17381743 (2008).

14) F. Sato, Y. Yamada and S. Sato, Chem. Lett., 41, 593-594 (2012).

15) P. X. Huang, F. Wu, B. L. Zhu, G. R. Li, Y. L. Wang, X. P. Gao, H. Y. Zhu, T. Y. Yan, W. P. Huang, S. M. Zhang and D. Y. Song, J. Phys. Chem. B, 110, 1614-1620 (2006).

16) K. Zhou, X. Wang, X. Sun, Q. Peng and Y. Li, J. Catal., 229, 206-212 (2005).

17) H.-X. Mai, L.-D. Sun, Y.-W. Zhang, R. Si, W. Feng, H.-P. Zhang, H.-C. Liu and C.-H. Yan, J. Phys. Chem. B, 109, 24380-24385 (2005).

18) S. Zhong, S. Wang, H. Xu, H. Hou, Z. Wen, P. Li, S. Wang and R. Xu, J. Mater. Sci., 44, 3687-3693 (2009).

19) T. Moeller and H. E. Kremers, Chem. Rev., 37, 97-159 (1945).

20) R. D. Shannon, Acta Crystallogr., A32, 751-767 (1976).

21) M. Hesse, H. Meier and B. Zeeh, "Spectroscopic Methods in Organic Chemistry 2nd Edition", Translated by R. Dunmur and M. Murray Thieme, Stuttgart (2008) pp. 49.

22) K. Momma and F. Izumi, J. Appl. Crystallogr., 44, 1272-1276 (2011). 